\title{
Association between the COMT Val158Met Genotype and Alzheimer's Disease in the Han Chinese Population
}

\author{
Yong Jia,b Zhihong Shia,b Mengyuan Liua Shuai Liu ${ }^{a} \quad$ Shuling Liu ${ }^{a}$ \\ Jinhuan Wang ${ }^{a, b}$ \\ a Key Laboratory of Cerebral Vascular Disease and Neurodegenerative Disease, and \\ ${ }^{b}$ Department of Neurology, Tianjin Huanhu Hospital, Tianjin, China
}

Key Words

Catechol-O-methyltransferase $\cdot$ Apolipoprotein E · Polymorphism · Alzheimer's disease

\begin{abstract}
Background: Alzheimer's disease (AD) is the leading cause of dementia worldwide and is associated with individual, familial and social burdens. Catechol-O-methyltransferase (COMT) may have a prominent role in AD pathophysiology by affecting the metabolism of catecholamine neurotransmitters and estrogen. Although the COMT rs4680 gene polymorphism has been investigated as a susceptibility factor for $A D$, the results are inconsistent. The aim of this study was to examine the influence of the COMT rs4680 gene polymorphism as a risk factor for $A D$ in the Han Chinese population and its synergistic effect with the apolipoprotein $E$ (APOE) gene. Methods: A total of 137 AD patients and 194 healthy controls were analyzed. Clinical criteria and neuropsychological tests were used to establish diagnostic groups. All subjects were analyzed for the COMT rs4680 polymorphism and APOE genotype. Results: No significant differences were observed between $A D$ and control subjects regarding the COMT genotype frequencies of $\mathrm{Val} / \mathrm{Val}, \mathrm{Val} / \mathrm{Met}$ and Met/Met, but Met alleles were higher in $A D$ than in control subjects (35.4 and $28.1 \%, p=0.045$ ). A minor synergistic effect between the genotypes GG and APOE \&4 was observed in AD patients (OR: $5.707,95 \%$ CI: $2.505-13.002$, $p<0.001)$. This synergistic effect was greater in women, who showed higher OR of AD (16.007, 95\% CI: 4.606-56.118, p < 0.001) versus the AD group with APOE \&4 (11.972, 95\% CI: $5.534-$ 25.902, $\mathrm{p}<0.001$ ). Furthermore, the COMT Met allele was an independent risk factor for AD without $A P O E$ \&4 allele carriers (OR: $1.806,95 \% \mathrm{CI}: 1.160-2.810, \mathrm{p}=0.009$ ), especially in men (OR: 4.904, 95\% CI: 2.381-10.099, p < 0.001). Conclusion: The COMT (Val158Met) polymorphism is not an independent risk factor for $A D$ but shows a synergistic effect between the genotypes $\mathrm{GG}$ and $A P O E \varepsilon 4$ that proves greater in women with $\mathrm{AD}$. The COMT Met allele represents a risk factor in $A D$ without $A P O E$ \&4 allele carriers, which is notable in men with $A D$.
\end{abstract}




\section{Introduction}

Alzheimer's disease (AD) is the most common cause of dementia in the elderly [1], affecting more than 35 million people globally. The incidence of AD doubles every 5 years after the age of 65 , with 1,275 new cases diagnosed per year per 100,000 persons older than 65 . AD affects $30-50 \%$ of the total population by the age of 85 [2]. AD clinically presents as progressive cognitive decline that affects memory, mood and behavior. The disease is characterized by extracellular formation of $A \beta$ amyloid plaques and intracellular neurofibrillary tangles in specific cortical areas. This process leads to neuronal loss, white matter degeneration, amyloid angiopathy, inflammation and oxidative damage [3].

Genetic, metabolic and environmental factors play a role in AD. The apolipoprotein E (APOE) $\varepsilon 4$ allele is the strongest genetic risk factor for sporadic forms of $\mathrm{AD}$ [4]. However, the $A P O E$ gene explains only a fraction of the genetic risk associated with AD. The catechol-Omethyltransferase (COMT) gene is located on chromosome 22q11. Discovered in 1958 [5], the gene produces an important enzyme in catecholamine biochemistry and pharmacology. COMT catalyzes the transfer of a methyl group from S-adenosyl-methionine to a hydroxyl group on a catechol nucleus [6] with a key function in catecholamine degradation (e.g., dopamine, noradrenaline and adrenaline) [7]. A common polymorphism (rs4680, G to A) in the COMT coding region causes a valine (Val) substitution to methionine (Met) and is responsible for variations in enzyme function. The Val/Val genotype leads to a three- to fourfold higher activity of the COMT enzyme compared with the Met/Met genotype, and the Val/Met genotype shows intermediate activity [8-11].

COMT plays a prominent role in AD pathophysiology by affecting the metabolism of catecholamine neurotransmitters and estrogen. The COMT gene regulates dopamine levels in the prefrontal cortex, which affects working memory and executive function [12]. Impaired executive functioning was reported in a subgroup of $\mathrm{AD}$ patients and was associated with a more severe disorder, rapid disease progression and a shorter survival period [13]. Although the COMT rs4680 gene polymorphism has been investigated as a susceptibility factor for AD, the results are inconsistent.

The aim of the present study was to determine whether the COMT Val158Met polymorphism is a genetic risk factor for AD in the Han Chinese population and what its synergistic effect with the APOE gene is. Samples were obtained from a group of AD patients and healthy individuals as controls. All subjects were analyzed for the COMT Val158Met (rs4680) polymorphism and $A P O E$ genotypes.

\section{Materials and Methods}

\section{Subjects and Diagnosis}

A total of 137 AD patients were recruited at Huanhu Hospital in Tianjin, China, between 2010 and 2013. All subjects underwent an extensive diagnosis and behavioral assessment by trained neurologists. An AD diagnosis was made according to the National Institute of Neurological and Communicative Disorders and Stroke - Alzheimer's Disease and Related Disorders Associations (NINCDS-ADRDA) for the diagnosis of probable AD criteria [14] and the Diagnostic and Statistical Manual of Mental Disorders (DSM-IV) criteria [15] for dementia. No familial cases of AD were included in this study. To avoid the inclusion of vascular dementia cases, patients who scored more than two points on the Hachinski ischemic scale were excluded [16].

The diagnosis of AD was based on medical and family histories, age of onset for dementia, neurological examination, and routine blood tests (e.g., biochemistry, vitamin B12 levels, hematology, syphilis and HIV serology). All AD patients had characteristic features on MRI 
Ji et al:: Association between the COMT Val158Met Genotype and Alzheimer's Disease in the Han Chinese Population

and CT scans. Definitive diagnosis required positron emission tomography with 11CarbonPittsburgh compound B (11C-PIB) and fluoro-18-deoxgyglucose imaging in several patients. Subjects were evaluated using a broad battery of neuropsychological tests, including the Mini-MentalState Examination,Clinical Dementia Rating scale, Montreal Cognitive Assessment and Neuropsychiatric Inventory.

Exclusion criteria included the following: (a) cerebrovascular disorders, intracranial mass or hydrocephalus documented by CT or MRI within the past 12 months; (b) history of schizophrenia, delusional disorder, mood disorder with psychotic features or mental retardation according to DSM-IV criteria; (c) abnormalities in syphilis serology, serum folate, vitamin B12, or thyroid hormone levels; (d) history of traumatic brain injury, Parkinson's or Huntington's disease, and (e) lack of a knowledgeable subject who was able to report on the patient's behavior.

A total of 194 elderly, healthy controls were selected from the Tianjin community. The controls underwent extensive clinical examinations to ensure that there was no personal or family (first-degree relatives) history of neurological or psychiatric conditions or presence of organic diseases involving the central or peripheral nervous systems. These subjects scored within the normal ranges for age and educational levels in psychometric testing, with Clinical Dementia Rating scores of 0.

Informed written consent was obtained from all subjects and their relatives. The study was approved by the Huanhu Hospital Ethics Committee.

\section{Genetic Analysis}

On the first visit, venous blood samples were collected in EDTA vacuum tubes. Genomic DNA from each subject was isolated from peripheral nuclear blood cells using the Omega blood DNA kit according to the manufacturer's instructions (Omega Bio-Tek Inc.). Polymerase chain reaction (PCR) was performed in a total volume of $25 \mu \mathrm{l}$ containing $1 \mu \mathrm{l}$ of the DNA template (30-60 ng/ $\mu \mathrm{l}), 2.5 \mu \mathrm{l} 10 \times$ Taq buffer, $0.5 \mu \mathrm{l}$ of dNTP mixture $(10 \mathrm{~mm}), 0.5 \mu \mathrm{l}$ of Taq DNA polymerase $\left(1 \mathrm{U} / \mu \mathrm{l}\right.$, Thermo Scientific), $2 \mu \mathrm{l}$ of each primer $(10 \mu \mathrm{M})$ and $\mathrm{ddH}_{2} \mathrm{O}$. PCR was performed using a Bioer thermal cycler system demo. The primer oligonucleotides used for COMT amplification were 5'-TACTGTGGCTACTCAGCTGTGC-3' (forward) and 5'-GTGAACGTGGTGTGAACACC-3' (reverse). Amplification conditions were initiated at $94^{\circ} \mathrm{C}$ for $5 \mathrm{~min}$, followed by 40 cycles of denaturation at $94^{\circ} \mathrm{C}$ for $30 \mathrm{~s}$, annealing at $56^{\circ} \mathrm{C}$ for $30 \mathrm{~s}$ and extension at $72{ }^{\circ} \mathrm{C}$ for $30 \mathrm{~s}$, with a final extension step at $72^{\circ} \mathrm{C}$ for $5 \mathrm{~min}$. The PCR products contained the Val158Met variation, which was differentiated using NlaIII restriction fragment length polymorphism analysis based on $12 \%$ polyacrylamide gel electrophoresis. The expected products after digestion were a Val/Val homozygote (114 bp), a Val/Met heterozygote (114 and $96 \mathrm{bp}$ ), and a Met/Met homozygote (96 bp) [17]. The APOE gene was amplified by PCR as described in detail by Ji et al. [18].

\section{Statistical Analysis}

Differences among demographic and clinical variables were evaluated using the $t$ test. A dichotomous variable was used for each polymorphism: ' 1 ' or ' 0 ' for 'carrier' or 'non carrier' of the $A P O E$ \& 4 allele and for different alleles and genotypes of the COMT gene. The frequencies of $A P O E \& 4$ and COMT genotypes and alleles in AD versus control subjects were compared using the standard $\chi^{2}$ test.

A binary regression model was created in order to determine the independent effect of any COMT allele and genotypes in the absence of the $\varepsilon 4$ allele, the effect of the $\varepsilon 4$ allele in the total sample, and a sample selected by at least one $\varepsilon 4$ allele and no COMT Met allele. Another model was created to evaluate the combined effect of the $\varepsilon 4$ allele and COMT genotypes, based on the hypothesis that the effect of estrogens might exist only in $\varepsilon 4$ carriers. p values of less than 0.05 were considered statistically significant. 
Table 1. Allele and genotype frequencies in $\mathrm{AD}$ patients and healthy controls

\begin{tabular}{|c|c|c|c|c|}
\hline & & $\begin{array}{l}A D, n(\%) \\
(n=137)\end{array}$ & $\begin{array}{l}\text { Control, } \mathrm{n}(\%) \\
(\mathrm{n}=194)\end{array}$ & $\mathrm{p}\left(\chi^{2}\right)$ \\
\hline \multirow[t]{7}{*}{ COMT } & Genotype & & & $0.071(5.300)$ \\
\hline & $\mathrm{GG}$ & $58(42.3)$ & $97(50.0)$ & \\
\hline & GA & $61(44.5)$ & 85 (43.8) & \\
\hline & AA & $18(13.1)$ & $12(6.2)$ & \\
\hline & Allele & & & $0.045(4.002)$ \\
\hline & A & $97(35.4)$ & 109 (28.1) & \\
\hline & G & 177 (64.6) & 279 (71.9) & \\
\hline \multirow[t]{10}{*}{ APOE } & Genotype & & & $0.000(43.790)$ \\
\hline & E2/E3 & $9(6.6)$ & 27 (13.9) & \\
\hline & E3/E3 & $69(50.4)$ & $144(74.2)$ & \\
\hline & E2/E4 & $1(0.7)$ & 0 & \\
\hline & E3/E4 & $48(35.0)$ & $21(10.8)$ & \\
\hline & $\mathrm{E} 4 / \mathrm{E} 4$ & $10(7.3)$ & $2(1.0)$ & \\
\hline & Allele & & & $0.000(47.628)$ \\
\hline & E2 & $10(3.6)$ & $27(7.0)$ & \\
\hline & E3 & 195 (71.2) & $336(86.6)$ & \\
\hline & $\mathrm{E} 4$ & $69(25.2)$ & $25(6.4)$ & \\
\hline
\end{tabular}

Two-tailed $\chi^{2}$ test for genotype distribution or allele frequency between $\mathrm{AD}$ patients and controls.

\section{Results}

There were no significant differences in age and gender between the AD and control groups. The mean age was $69.47 \pm 7.45$ years in the $\mathrm{AD}$ group and $68.38 \pm 6.56$ years in the control group ( $\mathrm{p}=0.096)$, while gender distributions $(M / F)$ were $63 / 74$ in the AD group and $77 / 117$ in the control group ( $\mathrm{p}=0.254)$.

The distribution of the COMT and APOE genotypes and the corresponding allele frequencies in $\mathrm{AD}$ and control subjects are shown in table 1 . The allele and genotype frequencies of COMT and $A P O E$ in $\mathrm{AD}$ and controls were in agreement with the HardyWeinberg equilibrium $(\mathrm{p}>0.05)$. No significant differences were found between $A D$ and control subjects regarding the genotype frequencies of $\mathrm{Val} / \mathrm{Val}, \mathrm{Val} / \mathrm{Met}$ and Met/Met $\mathrm{p}=$ $0.069, \chi^{2}=5.340$ ). However, the Met allele frequency was higher in AD than in control subjects $\left(\mathrm{p}=0.045, \chi^{2}=4.002\right)$. The differences proved significant for the APOE gene. The frequency of the $A P O E \& 4$ allele was, as expected, higher in the AD sample than in the control subjects.

In our survey, the APOE $\varepsilon 4$ allele was a risk factor for AD (OR: 5.624, 95\% CI: 3.2419.759). The COMT Met allele (GA+AA genotypes) did not seem to represent a risk factor for AD (OR: 1.362, 95\% CI: 0.877-2.116, $\mathrm{p}=0.169$ ). To avoid combined effects, we selected a subgroup of $\mathrm{AD}$ and control subjects with the presence of at least one COMT Met allele and the absence of the APOE \&4 allele. The results showed that the COMT Met allele was an independent risk factor in the subgroup with an absent APOE $\varepsilon 4$ allele. The OR of the AD patients was 1.806 (95\% CI: 1.160-2.810, $\mathrm{p}=0.009$ ) (table 2).

To evaluate whether an interaction between COMT and APOE occurs, we applied a binary logistic regression model after having subclassified the samples according to the COMT genotypes (AA+AG and $\mathrm{GG}$ ) and the presence of at least one $A P O E \varepsilon 4$ allele. A minor synergistic effect between the COMT GG genotypes with APOE $\varepsilon 4$ was observed in AD patients (OR: 5.707, 95\% CI: 2.505-13.002, p < 0.001) (table 2). When the samples were subclassified by gender, 


\section{Dementia}

Table 2. Binary logistic regression model of the risk factors for $\mathrm{AD}$

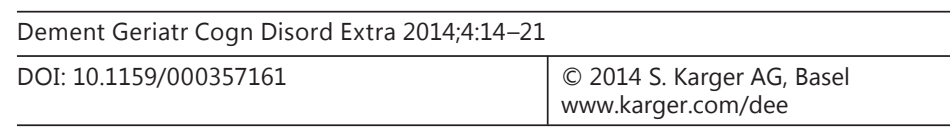

Ji et al.: Association between the COMT Val158Met Genotype and Alzheimer's Disease in the Han Chinese Population

\begin{tabular}{llll}
\hline & OR & $95 \% \mathrm{CI}$ & p value \\
\hline Independent risk factor & & & \\
A+ & 1.362 & $0.877-2.116$ & 0.169 \\
E4+ & 5.624 & $3.241-9.759$ & 0.000 \\
E4+A- & 5.707 & $2.505-13.002$ & 0.000 \\
E4-A+ & 1.806 & $1.160-2.810$ & 0.009 \\
Synergistic effect & & & \\
$\quad$ E4+ (AA+AG) & 3.637 & $1.882-7.029$ & 0.000 \\
E4+GG & 5.707 & $2.505-13.002$ & 0.000 \\
\hline
\end{tabular}

Table 3. Gender effects

\begin{tabular}{|c|c|c|c|c|}
\hline & $\begin{array}{l}\text { Men, OR }(95 \% \text { CI }) \\
(n=63)\end{array}$ & $\mathrm{p}$ value & $\begin{array}{l}\text { Women, OR }(95 \% \text { CI }) \\
(n=74)\end{array}$ & $\mathrm{p}$ value \\
\hline \multicolumn{5}{|c|}{ Independent risk factor } \\
\hline $\mathrm{A}+$ & $2.867(1.429-5.753)$ & 0.003 & $0.785(0.438-1.406)$ & 0.415 \\
\hline E4+ & $2.167(0.950-4.936)$ & 0.066 & $11.972(5.534-25.902)$ & 0.000 \\
\hline $\mathrm{E} 4+\mathrm{A}-$ & $1.241(0.343-4.496)$ & 0.742 & $16.077(4.606-56.118)$ & 0.000 \\
\hline $\mathrm{E} 4-\mathrm{A}+$ & $4.904(2.381-10.099)$ & 0.000 & $0.877(0.489-1.573)$ & 0.659 \\
\hline \multicolumn{5}{|l|}{ Synergistic effect } \\
\hline $\mathrm{E} 4+(\mathrm{AA}+\mathrm{AG})$ & $2.600(0.968-6.983)$ & 0.058 & $4.707(1.938-11.432)$ & 0.001 \\
\hline $\mathrm{E} 4+\mathrm{GG}$ & $1.241(0.343-4.496)$ & 0.742 & $16.077(4.606-56.118)$ & 0.000 \\
\hline
\end{tabular}

this synergistic effect was most notable in women carrying the COMT GG genotype and one of the $A P O E$ \&4 alleles, which showed a higher OR of the AD group (16.077, 95\% CI: 4.60656.118, $\mathrm{p}<0.001$ ) versus that of the AD group with APOE $\varepsilon 4$ (11.972, 95\% CI: 5.534-25.902, $\mathrm{p}<0.001$ ). Furthermore, the COMT Met allele represented a risk factor in men with AD (OR: 2.867, 95\% CI: 1.429-5.753, $\mathrm{p}=0.002$ ), especially in the subgroup with no APOE \&4 allele carriers (OR: 4.904, 95\% CI: 2.381-10.099, p < 0.001) (table 3).

\section{Discussion}

There was no significant difference between the AD patients and controls regarding the COMT genotype frequencies of Val/Val, Val/Met, Met/Met $\left(p=0.071, \chi^{2}=5.300\right)$, but the frequency of the Met allele was higher in AD than in the controls ( $\left.p=0.045, \chi^{2}=4.002\right)$. A minor synergistic effect between the genotypes $\mathrm{Val} / \mathrm{Val}$ with APOE $\varepsilon 4$ was observed in the AD patients. This synergistic effect was most notable in women carrying the COMT Val/Val genotype and one of the APOE $\varepsilon 4$ alleles, which showed a higher OR of the AD group (16.077, 95\% CI: 4.606-56.118, p < 0.001) versus the AD group with APOE $\varepsilon 4(11.972,95 \%$ CI: $5.534-$ 25.902, $\mathrm{p}<0.001$ ). Furthermore, the COMT Met allele was an independent risk factor in AD without $A P O E \varepsilon 4$ allele carriers (OR: $1.806,95 \% \mathrm{CI}: 1.160-2.810, \mathrm{p}=0.009$ ), especially in men (OR: 4.904, 95\% CI: 2.381-10.099, p < 0.001).

The COMT Met allele frequencies in healthy controls were similar to previously reported data in the Han Chinese population $[19,20]$ but different from frequencies reported in western populations [21-23]. In our sample, just as in other studies of the Han Chinese population, the frequency of the COMT Met/Met low-activity genotype was very low in healthy controls 
(6.9\%) and $\mathrm{AD}(14.2 \%)$. It is very difficult to extract the Met/Met genotype alone to study the influence on AD. Therefore, in our study, the combined Met/Met and Met/Val genotypes were analyzed.

Although several studies have evaluated the role of the COMT polymorphism as a possible risk factor for AD [21-25], the results are inconsistent. Forero et al. [21] reported that the COMT Met/Met low-activity genotype was associated with sporadic AD in males, but this trend was not confirmed after correcting for multiple tests. The results of the present study are consistent with an increased risk of AD with no APOE $\varepsilon 4$ allele carriers due to the Met allele, especially in males. Estrogens have recently been implicated in the etiology of AD through an APOE-dependent mechanism. Effects of estrogen on the central nervous system are modulated via estrogen receptors and metabolites. Thornton et al. [25] suggested that elevated estrone levels significantly increase the risk of AD in both men and women, but that it is not related to the COMT genotype because COMT Val/Met heterozygotes that also carry the $A P O E \varepsilon 4$ allele may be at risk for AD. Wang et al. [22] reported that the COMT Val/Val genotype is not an independent risk factor for AD but has a synergistic effect in conjunction with the APOE $\varepsilon 4$ allele. Martínez et al. [23] and Lanni et al. [24] also reported similar synergistic effects between the APOE $\varepsilon 4$ allele and COMT in AD. Martínez et al. [23] found a gender effect, namely that in $\mathrm{AD}, C O M T-A P O E$ interaction was greater in women than in men. In our study, the gender effect was obvious in women as there were synergistic effects between the COMT Val/Val genotype and APOE $\varepsilon 4$ allele. In men, however, this effect was not significant.

However, our study also showed that the COMT Met allele was an independent risk factor for $\mathrm{AD}$ without $A P O E \varepsilon 4$ allele carriers, especially in men with AD. These results, however, have not been confirmed by other studies so far. At least these results confirmed that the gender effect was very obvious according to the APOE and COMT genes in AD.

COMT has been suggested as a candidate for susceptibility to AD-related psychosis. Borroni et al. [26] reported that the COMT rs $4680 \mathrm{Val}$ allele was a risk factor for AD-related psychosis. In subsequent studies, other single nucleotide polymorphisms were analyzed in addition to the rs 4680 polymorphism. Positive associations with psychosis were confirmed at the haplotype level $[27,28]$. An increasing body of evidence relates COMT to the declarative episodic memory, which is greatly impaired in AD. The COMT Met allele was characterized by opposite effects on hippocampal and parahippocampal activities in schizophrenic patients and healthy controls during memory performance evaluations [29]. The COMT rs4680 polymorphism was associated with differences in the verbal declarative memory [30] and general attention [31]. Executive function is impaired in some individuals with AD. Recent evidence suggests that improved performance in executive function evaluations is associated with longer survival in AD cohorts [32]. The influence of COMT variants on executive function performance, as reported in schizophrenia and bipolar disorder, has been consistently replicated in middle-aged and elderly individuals without mental disorders $[33,34]$.

In conclusion, our study demonstrates that the COMT (Val158Met) polymorphism is not an independent risk factor for AD but shows a synergistic effect with the APOE $\varepsilon 4$ allele that proves to be greater in women with $\mathrm{AD}$. The COMT Met allele represents a risk factor in $\mathrm{AD}$ without $A P O E \varepsilon 4$ allele carriers, which is notable in men with AD. Larger population-based studies and different clinical subgroups are needed to confirm these findings. 
Ji et al.: Association between the COMT Val158Met Genotype and Alzheimer's Disease in the Han Chinese Population

\section{References}

1 Querfurth HW, LaFerla FM: Alzheimer's disease. N Engl J Med 2010;362:329-344.

-2 Hirtz D, Thurman DJ, Gwinn-Hardy K, Mohamed M, Chaudhuri AR, Zalutsky R: How common are the 'common' neurologic disorders? Neurology 2007;68:326-337.

-3 Montine TJ, Phelps CH, Beach TG, Bigio EH, Cairns NJ, Dickson DW, Duyckaerts C, Frosch MP, Masliah E, Mirra SS, Nelson PT, Schneider JA, Thal DR, Trojanowski JQ, Vinters HV, Hyman BT; National Institute on Aging; Alzheimer's Association: National Institute on Aging-Alzheimer's Association guidelines for the neuropathologic assessment of Alzheimer's disease: a practical approach. Acta Neuropathol 2012;123:1-11.

- 4 Corder EH, Saunders AM, Strittmatter WJ, Schmechel DE, Gaskell PC, Small GW, Roses AD, Haines JL, PericakVance MA: Gene dose of apolipoprotein E type 4 allele and the risk of Alzheimer's disease in late onset families. Science 1993;261:921-923.

5 Axelrod J, Tomchick R: Enzymatic 0-methylation of epinephrine and other catechols. J Biol Chem 1958;233: 702-705.

-6 Weinshilboum RM, Otterness DM, Szumlanski CL: Methylation pharmacogenetics: catechol-0-methyltransferase, thiopurine methyltransferase, and histamine-N-methyltransferase. Annu Rev Pharmacol Toxicol 1999; 39:19-52.

7 Gogos JA, Morgan M, Luine V, Santha M, Ogawa S, Pfaff D, Karayiorgou M: Catechol-O-methyltransferase-deficient mice exhibit sexually dimorphic changes in catecholamine levels and behavior. Proc Natl Acad Sci USA 1998;95:9991-9996.

8 Chen J, Lipska BK, Halim N, Ma QD, Matsumoto M, Melhem S, Kolachana BS, Hyde TM, Herman MM, Apud J, Egan MF, Kleinman JE, Weinberger DR: Functional analysis of genetic variation in catechol-0-methyltransferase (COMT): effects on mRNA, protein, and enzyme activity in postmortem human brain. Am J Hum Genet 2004; 75:807-821.

-9 Zubieta JK, Heitzeg MM, Smith YR, Bueller JA, Xu K, Xu Y, Koeppe RA, Stohler CS, Goldman D: COMT val158met genotype affects mu-opioid neurotransmitter responses to a pain stressor. Science 2003;299:1240-1243.

-10 Lachman HM, Morrow B, Shprintzen R, Veit S, Parsia SS, Faedda G, Goldberg R, Kucherlapati R, Papolos DF: Association of codon 108/158 catechol-0-methyltransferase gene polymorphism with the psychiatric manifestations of velo-cardio-facial syndrome. Am J Med Genet 1996;67:468-472.

$\checkmark 11$ Hagen K, Stovner LJ, Skorpen F, Pettersen E, Zwart JA: The impact of the catechol-0-methyltransferase Val158Met polymorphism on survival in the general population - the HUNT study. BMC Med Genet 2007;8:34.

-12 Tunbridge EM, Bannerman DM, Sharp T, Harrison PJ: Catechol-0-methyltransferase inhibition improves setshifting performance and elevates stimulated dopamine release in the rat prefrontal cortex. J Neurosci 2004; 24:5331-5335.

13 Serretti A, Olgiati P: Catechol-0-methyltransferase and Alzheimer's disease: a review of biological and genetic findings. CNS Neurol Disord Drug Targets 2012;11:299-305.

14 McKhann G, Drachman D, Folstein M, Katzman R, Price D, Stadlan EM: Clinical diagnosis of Alzheimer's disease: report of the NINCDS-ADRDA Work Group under the auspices of Department of Health and Human Services Task Force on Alzheimer's Disease. Neurology 1984;34:939-944.

15 American Psychiatric Association: Diagnostic and Statistical Manual of Mental Disorders, ed 4, Text Revision. Washington, American Psychiatric Association, 2000, pp 157-158.

16 Rosen WE, Terry RD, Fuld PA, Katzman R, Peck A: Pathological verification of ischemic score in differentiation of dementias. Ann Neurol 1980;8:486-488.

17 Worda C, Sator MO, Schneeberger C, Jantschev T, Ferlitsch K, Huber JC: Influence of the catechol-0-methyltransferase (COMT) codon 158 polymorphism on estrogen levels in women. Hum Reprod 2003;18:262-266.

18 Ji Y, Liu M, Huo YR, Liu S, Shi Z, Liu S, Wisniewski T, Wang J: Apolipoprotein E $\varepsilon 4$ frequency is increased among Chinese patients with frontotemporal dementia and Alzheimer's disease. Dement Geriatr Cogn Disord 2013; 36:163-170.

19 Gao L, Li H, Li K, Shen Z, Liu L, Li C, Zhang Z, Liu Y: Polymorphism of the catechol-O-methyltransferase gene in Han Chinese patients with psoriasis vulgaris. Genet Mol Biol 2009;32:32-36.

20 Chen C, Chen C, Moyzis R, Dong Q, He Q, Zhu B, Li J, Li H, Li J, Lessard J: Sex modulates the associations between the COMT gene and personality traits. Neuropsychopharmacology 2011;36:1593-1598.

-21 Forero DA, Benitez B, Arboleda G, Yunis JJ, Pardo R, Arboleda H: Analysis of functional polymorphisms in three synaptic plasticity-related genes (BDNF, COMT AND UCHL1) in Alzheimer's disease in Colombia. Neurosci Res 2006;55:334-341.

22 Wang PN, Liu HC, Liu TY, Chu A, Hong CJ, Lin KN, Chi CW: Estrogen-metabolizing gene COMT polymorphism synergistic APOE epsilon4 allele increases the risk of Alzheimer disease. Dement Geriatr Cogn Disord 2005; 19:120-125.

23 Martínez MF, Martín XE, Alcelay LG, Flores JC, Valiente JM, Juanbeltz BI, Beldarraín MA, López JM, GonzalezFernández MC, Salazar AM, Gandarias RB, Borda SI, Marqués NO, Amillano MB, Zabaleta MC, de Pancorbo MM: The COMT Val158 Met polymorphism as an associated risk factor for Alzheimer disease and mild cognitive impairment in APOE 4 carriers. BMC Neurosci 2009;10:125.

24 Lanni C, Garbin G, Lisa A, Biundo F, Ranzenigo A, Sinforiani E, Cuzzoni G, Govoni S, Ranzani GN, Racchi M: Influence of COMT Val158Met polymorphism on Alzheimer's disease and mild cognitive impairment in Italian patients. J Alzheimers Dis 2012;32:919-926. 
25 Thornton V, Warden D, Talbot C, Mastana SS, Bandelow S, Hogervorst E: Modification of estrogen's association with Alzheimer's disease risk by genetic polymorphisms. Brain Res 2011;1379:213-223.

26 Borroni B, Agosti C, Archetti S, Costanzi C, Bonomi S, Ghianda D, Lenzi GL, Caimi L, Di Luca M, Padovani A: Catechol-O-methyltransferase gene polymorphism is associated with risk of psychosis in Alzheimer Disease. Neurosci Lett 2004;370:127-129.

-27 Borroni B, Grassi M, Costanzi C, Zanetti M, Archetti S, Franzoni S, Caimi L, Padovani A: Haplotypes in cathechol0-methyltransferase gene confer increased risk for psychosis in Alzheimer disease. Neurobiol Aging 2007;28: 1231-1238.

28 Sweet RA, Devlin B, Pollock BG, Sukonick DL, Kastango KB, Bacanu SA, Chowdari KV, DeKosky ST, Ferrell RE: Catechol-O-methyltransferase haplotypes are associated with psychosis in Alzheimer disease. Mol Psychiatry 2005;10:1026-1036.

29 Di Giorgio A, Caforio G, Blasi G, Taurisano P, Fazio L, Romano R, Ursini G, Gelao B, Bianco LL, Papazacharias A, Sinibaldi L, Popolizio T, Bellomo A, Bertolino A: Catechol-O-methyltransferase Val(158)Met association with parahippocampal physiology during memory encoding in schizophrenia. Psychol Med 2011;41:1721-1731.

30 Harris SE, Wright AF, Hayward C, Starr JM, Whalley LJ, Deary IJ: The functional COMT polymorphism, Val 158 Met, is associated with logical memory and the personality trait intellect/imagination in a cohort of healthy 79 year olds. Neurosci Lett 2005;385:1-6.

-31 Liu ME, Hong CJ, Liou YJ, Tsai YL, Hsieh CH, Tsai SJ: Association study of a functional catechol-0-methyltransferase polymorphism and executive function in elderly males without dementia. Neurosci Lett 2008;436: 193-195.

32 Zhou B, Zhao Q, Teramukai S, Ding D, Guo Q, Fukushima M, Hong Z: Executive function predicts survival in Alzheimer disease: a study in Shanghai. J Alzheimers Dis 2010;22:673-682.

33 de Frias CM, Annerbrink K, Westberg L, Eriksson E, Adolfsson R, Nilsson LG: Catechol-0-methyltransferase Val158Met polymorphism is associated with cognitive performance in nondemented adults. J Cogn Neurosci 2005;17:1018-1025.

34 Wishart HA, Roth RM, Saykin AJ, Rhodes CH, Tsongalis GJ, Pattin KA, Moore JH, McAllister TW: COMT Val158Met genotype and individual differences in executive function in healthy adults. J Int Neuropsychol Soc 2011;17: 174-180. 